Article

\title{
Energy Consumption and Usage Reduction in Lecture Halls, Kwame Nkrumah University of Science and Technology
}

\author{
Pius Nimoh ${ }^{1}$, Daniel Duah ${ }^{2 *}$, Alexander Marful ${ }^{2}$ \\ 1 Department of Architecture, Kwame Nkrumah University of Science and Technology; Kumasi-Ghana \\ graduatestudies@knust.edu.gh \\ * Correspondence: amarful.yahoo.com or piusnimoh12@gmail.com; Tel.: (+233- 5021-05309, +233- 5461-19524)
}

\begin{abstract}
All over the world energy is used for different purposes and hence its continuous high demand which has brought about an increase in crisis and prices of energy. Ghana has faced a lot of supply and high electricity consumption challenges over a period of time. The Energy Commission of Ghana has developed regulations and guidelines to help reduce high consumption challenges among users, these included the replacement of incandescent bulbs with fluorescent bulbs, ban of importation of low energy efficient appliances. In spite of the effort to reduce electricity wastage, there is still a high increase in electricity consumption. The research investigated what contributed to electricity consumption in Kwame Nkrumah University of Science and Technology with the lecture halls as the main focus, the research also analyzed the current occupant behavior characterized by the electrical energy consumption practices. And investigated how the contemporary theories for reducing energy consumption was used in the lecture halls. A questionnaire survey was conducted to investigate occupants on their energy use practices in lecture halls that causes wastages, observation was made to establish relevant data on the use of contemporary theories for energy reduction in lecture halls. In a total of 110 occupants that responded to the questionnaire, 79 occupants almost always turn off electrical fitting and fixtures when not in use. From the responses, a majority of the occupants claimed to comply to best practices of energy use. The research concluded that some contemporary theories to reduce energy consumptions was not used and considered in the lecture halls. Keywords: Electricity efficiency, Occupant behavior, Lecture halls
\end{abstract}

Keywords: Electric energy; Occupant behavior; energy efficiency; lecture halls

\section{Introduction}

All over the world energy is used in performing different kinds of activities hence its high demand. In Ghana, the energy crisis has caused so much damage to industries, businesses, and some institutions and has also prevented the efficient productivity of goods and services [1]. According to the World Energy Council (2010) [2], energy consumption will be directly proportional to the increasing population and economic growth of a country in some years to come. Ghana has faced a lot of supply and transmission challenges and high electricity consumption levels over a period of time. In 2006, the Energy Commission was established to set guidelines and requirements for entities desiring to operate electricity supply to reduce transmission and supply challenges [3].

Also, the commission developed some code of regulations to tackle electricity wastage among users. These included the replacement of incandescent bulbs with fluorescent bulbs in households, and educational institutions, the ban of importation of low energy efficient appliances and making energy efficient appliances affordable for every citizen [4]. In spite of the effort to reduce electricity wastage, there is still a high increase in electricity 
consumption and wastage. Many schools are challenged by poor usage of energy and energy efficiency practices [5]. Is there any relationship between teaching and learning and high energy consumption? How can these relationships be understood? In response to the emerging gap in knowledge, this study investigates what contribute to electricity consumption in Kwame Nkrumah University of Science and Technology (KNUST) lecture halls. The main focus of this report is to contribute to the improvement of energy efficiency of lecture halls at KNUST.

An observational study on students has shown that students turn out to be reluctant in regulating electrical fixtures and appliances when not in use. And thus, most electrical fixtures are left on for a very longtime. Energy efficiency in buildings depends on the important degree to which the specific energies have been utilized [6]. Project at early stage design, key decisions normally made by the architect may have a significant effect on the subsequent possibilities of the energy usage of a building [7]. Improved systems in buildings minimize its need for mechanical cooling and thus maintain the building significantly reduces energy consumption.

Literature on energy savings that can be achieved by optimized building forms and designs, improved efficiencies of individual energy-using systems in buildings, and educated occupant behavior and the function of building systems are also some of the contemporary theories that are not regularly implemented in the lecture halls to enhance energy efficiency [8]. But these contemporary theories proposed by researchers are mostly overlooked.

The main objectives of this study are to

- Investigate the energy consumption practices and occupant behavior in the lecture halls.

- Identify contemporary theories for reducing electric energy wastage in lecture halls.

- Develop a tool that will be used to improve the energy efficiency in lecture halls.

This paper is organized in six sections. Section 2 shows an overview of electricity consumption practices in lecture halls, the relevance of the proper design of lecture halls, theories for reducing electric energy wastage and energy efficiency tools for design of lecture halls. Section 3 describes the quantitative approach in gathering data for the study. In Section 4, the documentation of results from occupants of lecture halls and management are presented. Section 5 analysis the results and compares them with data obtained from section 2. Conclusion and recommendation are drawn based on findings of the study in Section 6.

\section{Literature Review}

The broad area of energy consumption pattern can be narrowed to it wastage in lecture halls. The idea of this is to unveil all the variables in the subject to enable discussion of the situation in the study area.

2.1. Electric energy consumption practices and occupant behavior

\subsubsection{Electricity Wastage}


Educational institutions in America use an average of 18.9 kilowatt hours (kwh) and spend an average of $\$ 1.10$ per square foot yearly on electricity, contributing to an estimated 279 billion kwh of lighting use in the university sector [9]. Wasteful usage of electric energy in university buildings can be prevented because research rooms, lecture halls and offices still stay lit even though unoccupied, but this misuse can be reduced by incorporating effective behavioral improvement and mindset [10].

Although occupancy sensors can save 20 percent of the electricity required for illumination relative to manual switches alone, behavioral rewards provide a less costly and ultimately more viable and internationally available solution that can lead to rapid and free-standing decreases in annual energy bills [11]. During the construction or post-occupancy management process, the effect of building occupant activity on energy usage is normally not considered [12].

2.1.2. Occupancy behavioral impact on energy use

Total electric energy use of buildings showed major variations even in similar climates between buildings with the same purpose and located [13]. Occupant behavior is also one of the most significant sources of uncertainty in the prediction of building energy use. This is due to the complexity and inherent uncertainty of occupant behavior [14]. With the trend towards low energy buildings that reduce fossil fuel use and carbon emissions, getting occupants actively involved during the design and operation of buildings is a key to achieving high energy performance without threatening occupant comfort [15]. The occupancy behavior is categorized in three workstyles, and they are as follows; the austerity workstyle, the standard workstyle, and the wasteful workstyle. For the austerity occupant he turns off lights and HVAC and turns down plug-loads 30\% when he leaves office. Whilst the standard occupant operates lights, HVAC, and office equipment according to schedules. The wasteful occupant leaves $100 \%$ on when he leaves the office (Tianzhen, 2013). 


\begin{tabular}{|c|c|c|c|}
\hline Occupant behavior & $\begin{array}{l}\text { Austerity } \\
\text { workstyle }\end{array}$ & $\begin{array}{c}\text { Standard } \\
\text { workstyle }\end{array}$ & $\begin{array}{c}\text { Wasteful } \\
\text { workstyle }\end{array}$ \\
\hline Cooling setpoint $\left({ }^{\circ} \mathrm{C}\right)$ & 26 & 24 & 22 \\
\hline Heating setpoint $\left({ }^{\circ} \mathrm{C}\right)$ & 18 & 21 & 23 \\
\hline Adaptive comfort & Yes & None & None \\
\hline Occupancy controls & $\begin{array}{l}\text { If unoccupied, turn } \\
\text { off lights and } \\
\text { HVAC, turn down } \\
\text { plug-load } 30 \%\end{array}$ & Scheduled & $\begin{array}{l}\text { Leave everything } \\
\text { on: lights, HVAC, } \\
\text { and plug-load }\end{array}$ \\
\hline Daylighting Control & 3 Steps Dimming & None & None \\
\hline HVAC operation time & $\begin{array}{l}\text { Turn on } 1 \text { hour late } \\
\text { and turn off } 1 \text { hour } \\
\text { early: } 9 \text { am to } 4 \mathrm{pm}\end{array}$ & $\begin{array}{l}\text { Scheduled on: } \\
8 \text { am to } 5 \mathrm{pm}\end{array}$ & $\begin{array}{l}\text { Same as the whole } \\
\text { building schedule: } \\
6 \text { am to } 10 \mathrm{pm}\end{array}$ \\
\hline $\begin{array}{l}\text { Cooling startup } \\
\text { control }\end{array}$ & $\begin{array}{l}\text { Cooling turns on } \\
\text { when space air } \\
\text { temperature } \\
\text { reaches } 28^{\circ} \mathrm{C} \text {, then } \\
\text { maintains at } 24^{\circ} \mathrm{C} \text {. } \\
\text { Cooling turns off } \\
\text { when unoccupied. }\end{array}$ & $\begin{array}{l}\text { Follow HVAC } \\
\text { operation } \\
\text { schedule (8am } \\
\text { to } 5 \mathrm{pm} \text { ) to } \\
\text { maintain } 24^{\circ} \mathrm{C} \text {. } \\
\text { Same as above. }\end{array}$ & $\begin{array}{l}\text { Follow HVAC } \\
\text { operation schedule } \\
\text { (6am to } 10 \mathrm{pm} \text { ) to } \\
\text { maintain } 24^{\circ} \mathrm{C} \text {. } \\
\text { Same as above. }\end{array}$ \\
\hline Combined & $\begin{array}{l}\text { All above } \\
\text { behavior }\end{array}$ & $\begin{array}{l}\text { All above } \\
\text { behavior }\end{array}$ & $\begin{array}{l}\text { All above } \\
\text { behavior }\end{array}$ \\
\hline
\end{tabular}

Figure 1. Occupant behavior categorized into three groups

2.2. Profile of study area and energy consumption

2.2.1. Electric energy consumption in Kwame Nkrumah University of Science and Technology

The population increase in KNUST, has forced the input of more infrastructure such as residential halls, lecture halls and many other facilities. The only source of electric energy that powers the school is hydro power from Electricity company of Ghana. In regards to utilities, about eighty percent of electricity consumed by the university is used for mechanical cooling, of which most of them are energy inefficient and as such consumes more power. Besides air conditioners, the University has as many as 75,000 ceiling fans scattered in lecture halls and offices. As at now, Kwame Nkrumah University of Science and Technology spends $2.4 \mathrm{~m}$ Ghana cedi's on electricity monthly [17]. The school is currently owing Electricity Company of Ghana as a result of high electricity consumption and wastage.

2.3. General Consideration for the design of lecture halls

2.3.1. Nature of University lecture halls

Amongst the building structures in university campuses, the lecture halls hold all academic activities which is usually segregated from all other buildings to facilitate a conducive atmosphere for teaching and learning. Unlike conventional classrooms, with a capacity of twenty to forty, [18] describes academic lecture halls as being a large space where students acquire knowledge. Research shows that the capacity of lecture halls is usually measured in the hundreds.

2.3.2. Basic consideration in lecture hall design 
If facilities are built in compliance with standards, they establish an energy efficient building, provide an environment that promotes and encourages effective teaching and learning [19]. The concept of standard considerations for the design of the lecture hall were revealed by U. Isoa, 2013. These are:

2.3.2.1. General lighting system in lecture hall

M. Rachmawati [20] in his research pointed out that the amount of lighting received in a space is one of the most obvious indicators for the adequacy of an illumination system. He further defines illumination as the amount of light falling on the working plane or the object of attention. To achieve visual comfort (IES, CIBSE and DIN EN 12464), the general lighting system recommends a minimum of 500 lux for reading halls and a demonstration desk area of up to 750 lux in relation to the classroom area.

2.3.2.2. Ventilation systems in lecture hall

Ventilation is the substitution of used existing air with the outside air. It does have three major purposes which are, structural cooling, supply of fresh air and body cooling [21]. Wind pressure or mechanical means like fans, Stack effect, evaporative coolers and air conditioners can contribute to the moving of air through the building. Research shows that the shape, height, orientation and planning of buildings ventilation determines its air flow around buildings. Furthermore, external features and factors, as well as the number and size of openings also constitute to factors that affect air flow through buildings.

2.4. Theories for reducing electric energy wastage

2.4.1. Electrical energy efficiency measures

In Sustainable Development Goals, the preservation of the biosphere and provision of affordable, and sustainable energy is one of the most important aim to be accomplished. This require significant increase in the proportion of renewable energy in the international energy mix and doubling the worldwide speed of advance in energy efficiency. Gielen [22] stated that there are numerous benefits societies and countries can gain from energy efficiency, yet the major blockade to effective implantation is the change of behavior and mindset. Behavior change is of central importance in bringing about the significant reductions in energy end-use. In this study, it is intended to review some of the mechanisms that could contribute to sustainable behavioral change.

2.5. Increasing awareness in public spaces for behavioral change

Although education is vital in this regard, putting in place technical strategies to make the energy visible and tangible to prevent wastage becomes very important [23]. An evaluation of studies in the workplace proved that pro-environmental behaviors in this setting is dependent on both individual factors such as attitudes and organization specific influences, but shows that the interaction between individual and organizational factors lack proper understanding. It is recommended that intervening to promote proenvironmental behavior in the workplace should focus not only on physical facilitation, but also tailored persuasive communication and the active engagement of middle management (Staddon).

2.6 Case study for energy efficient tools for lecture halls

2.6.1. Electric energy consumption pattern- A case of Indian Institute of Technology, Bombay 
As a result of increased electricity bills between 2006 and 2007, an audit was carried out for the Indian Institute of Technology (IIT). The audit looked at different end-use energy consumption activities and identified, listed and assessed the potential energy conservation opportunities. The objective was to achieve savings of up to $20 \%$ in electrical energy consumption. The research shows that as of April 2008, this campus had a connected power capacity of 5.3 MW and a contract requirement of 4.5. The IIT energy bill for the year 2007 was Rs. 10.2 crores [24].

Strategic grouping with different focus areas and end uses was developed as a move to find out the causes of high demand for electricity. The groups below were formed;

Group 1: Lighting and fans in Lecture Halls and Offices

Group 2: Computers and other gadgets in Lecture Halls and Offices

Group 3: Lighting Common Area - Covering corridors, grounds, and washrooms

Group 4: Lecture hall air conditioners and central air conditioning

The groups were permitted to assist in the auditing activity by using various measuring instruments such as Power Demand Analyzers and Lux meters. The Electrical Maintenance Section also sought cooperation to collect past data and to take measurements.

\section{DISTRIBUTION OF CONNECTED LOAD BY END USE}

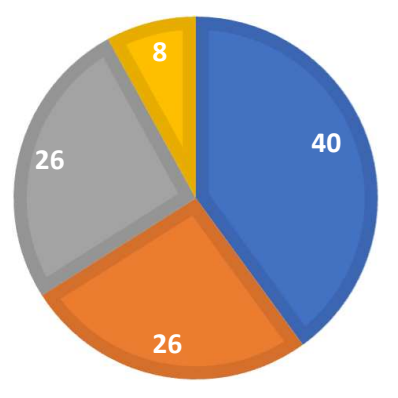

- Air Conditioning

a Lighting

a Fans

Computers and other gadgets

Figure 2. Distribution of connected end load by end-use

\section{Methodology}

The research method was identified based on strategies that can help translate concept and principles into guidelines that shows how the study is to be conducted. The focus was on the sampling technique, target group and sampling size determination.

\subsection{Literature search}

An extensive literature review and analysis on the energy audit of the Indian Institute of Technology- Bombay (IIT-B) [24]. has been presented in Chapter 2. The source of this information includes: the official web site of the Institute, published literature and journals from web pages of research gate. However, this literature serves as a guide to execute the survey in the lecture halls of KNUST.

\subsection{Sampling Size Determination}

Kotler and Roland [25] explains a sample as a part of a population selected as a proxy in the research. With a smaller population the resources are able to reach out to everyone. And with a sample, it makes everybody who matters to the survey accurately represented. 
In drawing the inference, the main interest is to understand that the sample can infer and apply across the entire population. Probability stratified random sampling technique is used in selecting respondents who will part of the sample. Stratified sampling is when an important characteristic of your research is divided and this creates a statistical feature. The population is then sampled randomly within each category [26].

Snowball sampling is a sampling technique which the odds of respondents being selected for the sample cannot be for. This sample is usually used in hidden populations. With the aid of virtual social network to allow respondents recruit colleagues into the sample is known as virtual snowball sampling [27].

With the aid of the virtual snowball sampling technique, data was collected from those who were readily available (students and lecturers) without a projected sampling size.

\subsection{Data Collection Methods}

Based on the objectives of the research, the areas of interest include:

- Formation of audit groups for specific areas, which include areas such as washrooms and corridors of lecture halls, are categorized as one group including the main lecture hall. Also, electrical fixtures and gadgets are assigned to the areas with respect to their types and efficiency.

- Visual inspection and data collection, the current conditions of electrical fixtures and gadgets are inspected to know if they are functioning or not. This is done by the turn on of fixtures for a period of time and recording those that are working and those that are not.

- Observation and general condition of the lecture hall equipment's and quantification, the electrical equipment in the lecture hall are quantified and grouped based on their types, function and efficiency.

- Verification of specific energy consumption of equipment's, detailed calculations, analyses and assumptions, validation and potential energy saving opportunities.

3.4. Development of Questionnaire

Two set of questionnaires was made available, one for users(students) and the other for the school management. The questionnaire was divided into two sections for the user(students). The first section looked at the background information of the user whilst the second section focuses on the user energy consumption practices. And for the Management the first section also looked at the background information about the respondent and the second energy efficiency practices. The research made use of Google Forms where a link was forwarded to occupants via WhatsApp and E-mail.

\subsection{Data Analysis}

The data was critically analyzed based on the research question in order to satisfy the purpose of the research. The raw data of the respondents was analyzed using a Statistical Package for Social Sciences (SPSS). The findings from the survey are tabulated and it explains the results to the questions.

\section{Results}

4.1. Users of lecture hall (students) responses 
This section documents the responses obtained from users of lecture halls (students) on their energy usage behaviors. Students were questioned to find out how they engaged in energy consumption practices in their daily activities in the lecture halls.

4.1.1. Demographic characteristics of users of the lecture halls

In all, 150 questionnaires were administered through Google Forms links. A total of 110 responses were received. This number consisted of males who recorded a total of 68 respondents and females who recorded a total of 42 respondents. Figure 3 below represents the gender distribution of the student respondents. The respondents were asked about their colleges of affiliation. A graphical representation of the respondents in according to their colleges is show in Figure 3.

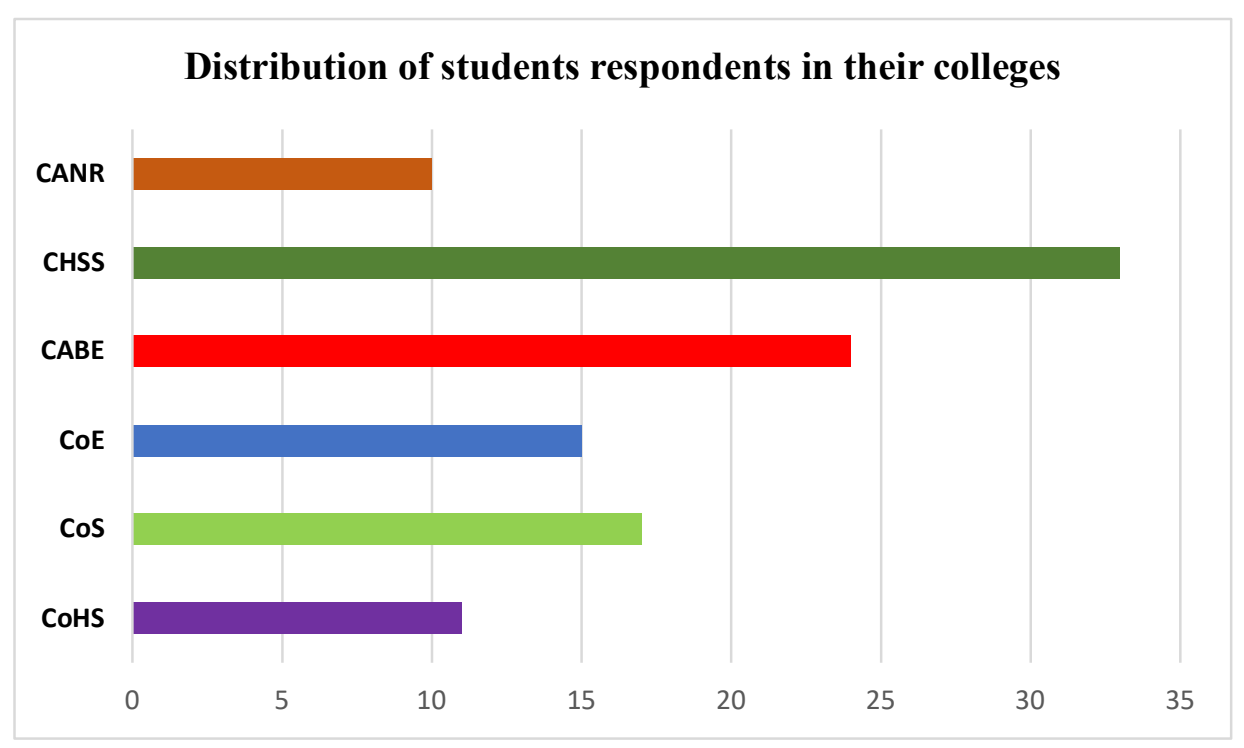

Figure 3. Distribution of student respondents per their colleges

4.1.2. Electrical Appliances Used

The survey revealed that users of lecture halls (students) possessing a number of electrical appliances. The personal appliances were laptop computers, mobile phones, tablets and the general or shared appliances were projectors, public address system, electric bulbs, ceiling fans and air condition system. The shared appliances are supplied by the lecture halls management and the lecturers. Figure 4 show the distribution of students' personal appliances in the lecture hall. 


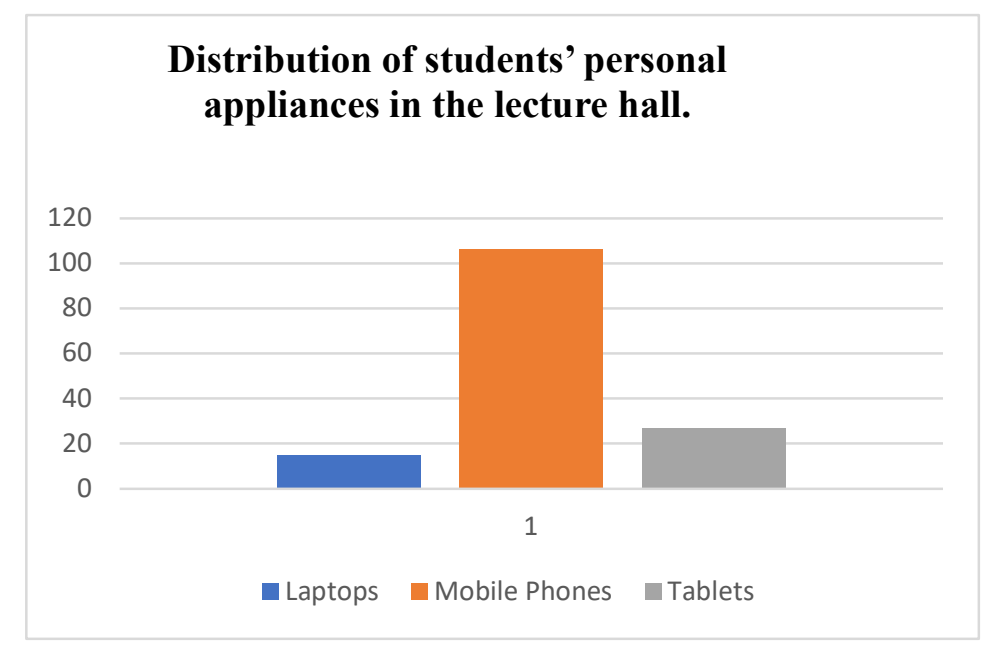

Figure 4. The distribution of students' personal appliances in the lecture hall.

\subsubsection{Energy Usage practice}

From the literature survey, a number of points were raised on behavior of building users of lecture halls (students) in the university that facilitated wastage of energy. Users of lecture halls (students) chose between four options (from Almost Always to Not at All) on a scale of agreement to describe their energy use practices. From the results, it was realized that respondents engaged in efficient habits as regards their energy use. The questions were asked concerning the use of fixed appliances provided by the lecture halls (light bulbs, ceiling fans, air conditioners) and the use of other gadgets used by users of lecture halls (students). Students' responses on some energy usage behaviors are presented in Table 1 below 


\section{BEHAVIOUR}

Leave laptop plugged in when not in use

Leave Mobile phone Plugged in when fully charged

Turn off fans when weather is cool

Turn off fans when leaving the lecture hall

Turn off lights when there is enough daylight

Turn off lights on corridors and washrooms when not needed

Turn off air conditioning when room temperature is moderate

Turn off air conditioning when leaving the lecture hall

Close windows and doors when air condition is in use Reporting electrical fault

\section{LEVEL OF AGREEMENT}

\begin{tabular}{|c|c|c|c|}
\hline \multirow[b]{2}{*}{ Almost always } & \multicolumn{3}{|c|}{ Not very } \\
\hline & Very Often & Often & Not at all \\
\hline 14 & 18 & 43 & 35 \\
\hline 17 & 16 & 38 & 39 \\
\hline 54 & 41 & 10 & 5 \\
\hline 28 & 37 & 26 & 19 \\
\hline 17 & 29 & 38 & 26 \\
\hline 47 & 30 & 18 & 15 \\
\hline 34 & 38 & 25 & 13 \\
\hline 49 & 40 & 10 & 11 \\
\hline 42 & 35 & 19 & 14 \\
\hline 40 & 37 & 20 & 13 \\
\hline
\end{tabular}

\section{Students' Responses on Energy usage Behaviours}

Table 1. Responses of Users of lecture halls (students)on the Energy usage behaviors

Table 1 above was further summarized using charts, into categories of behaviours such as:

1. Turn off appliance when not in use

2. Leave appliance plugged when fully charged

3. Switch off fixed appliances leaving lecture halls

Responses on the first category included responses on the questions: Turn off fans when weather is cool, turn off lights when there is enough daylight, turn off lights on corridors and washrooms when not needed and Turn off air conditioning when room temperature is moderate.

Figure 5 shows a pie chart for this category 


\section{Turn off appliance when not in use}

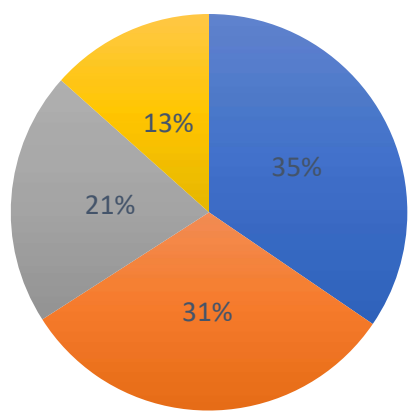

Almost always

Very Often

Not very Often $\quad$ Not at all

Figure 5. Responses of students on the Question of Turning Off Appliance When Not in use

From Figure 5 above, most students responded to have been turning of appliances almost always when not in use (35\%) while 13\% responded to have not been doing this at all. The second category, which included responses on the questions: Leave laptop plugged in when not in use and Leave Mobile Phone Plugged in when fully charged, is summarized in Figure 6 below.

\section{Leave appliance plugged when fully charged \\ Almost always \\ very Often \\ not very Often \\ - Not at all}

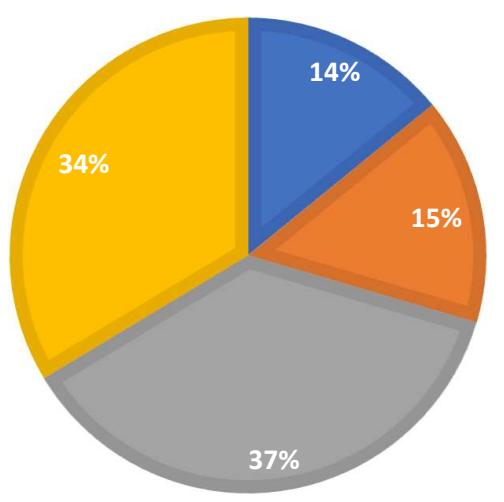

Figure 6. Responses of students on the Question of Leaving appliance plugged when fully charged 
Figure 6 above also shows that students professed to engage in energy conserving behaviors as most responded to have not been leaving appliances plugged in when not in use very often $(37 \%)$.

Lastly, the category of whether students switch of appliances when leaving the lecture hall is made up of response to questions such as: Turn off fans when leaving the lecture hall, turn off air condition when leaving the lecture hall. Figure 6 also shows the summary of the responses.

4.2. Management response

Management, comprising users of lecturers and heads of department other than students, were also involved in the data collection and analysis process. Questionnaires were administered to 30 members of the management in total. This number comprised one head of department and 4 lecturers from each of the six colleges in the institution.

\begin{tabular}{|l|r|r|r|r|}
\hline \multicolumn{1}{|c|}{ APPLIANCEUSE } & Almostalways & \multicolumn{3}{c|}{ Very Often Notvery Often Not at all } \\
\hline Leave laptop plugged in when not in use & 14 & 9 & 5 & 2 \\
\hline Leave Mobile phone Plugged in when fully charged & 13 & 7 & 9 & 1 \\
\hline Turn off Projector or hibernate when not in use & 7 & 6 & 14 & 3 \\
\hline Turn off PA system when notin use & 3 & 1 & 15 & 11 \\
\hline Turn off fans when weather is cool & 15 & 9 & 5 & 1 \\
\hline Turn off fans when leaving the lecture hall & 3 & 5 & 9 & 13 \\
\hline Turn off lights when there is enough daylight & 2 & 5 & 13 & 10 \\
\hline Turn off lights on corridors and washrooms when notneeded & 10 & 9 & 5 & 6 \\
\hline Turn off air conditioning when room temperature is moderate & 4 & 6 & 7 & 13 \\
\hline Turn off air condition when leaving the lecture hall & 10 & 8 & 10 & 2 \\
\hline Close windows and doors when air condition is in use & 14 & 10 & 4 & 2 \\
\hline Reporting electrical fault & 20 & 8 & 2 & 0 \\
\hline
\end{tabular}

Responses of management on energy wastage behaviors by management

Table 2. Management's Responses on Energy Wastage Practices in lecture halls

To further analyze these data, the researcher put them in categories of three: Reporting electrical faults to school electricians, turn off appliance when not in use or needed and 
Leave appliances plugged in when not in use. Figure 5, Figure 6 and Table 1 show the distribution of these categories.

\section{Turn off appliance when not in use}

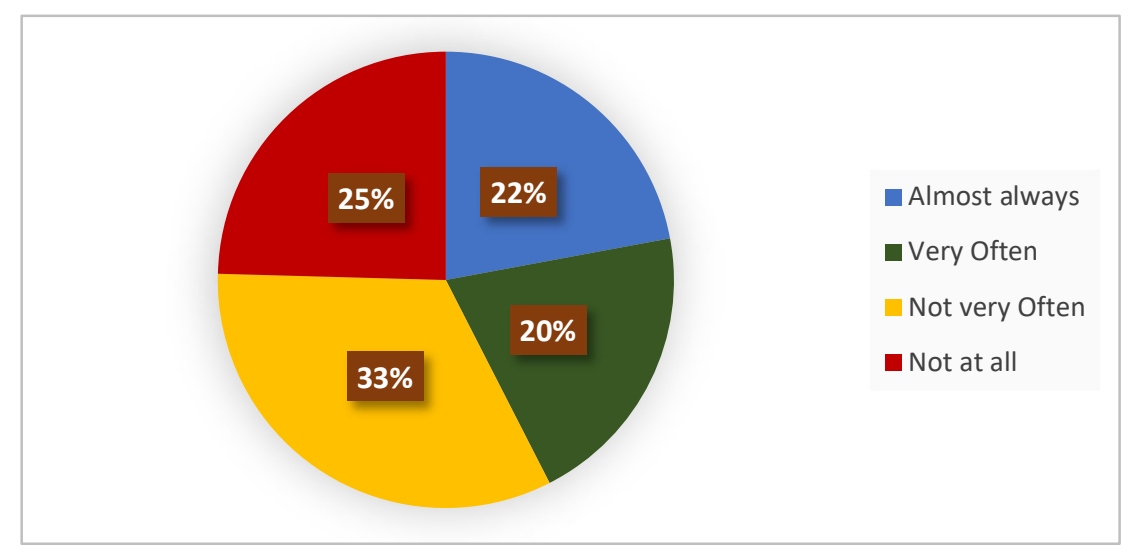

Figure 7. Management responses on the question: turn off appliance when not in use or needed

Figure 7 reveals that majority of the management respondents (33\%) did "Not Very Often" turn off appliances when not in use followed by $25 \%$ who did not turn appliances off at all when not in use. This could be mainly caused by their total focus on lecturing or presentations at the expense of energy conservation. This thus suggest that management admitted to culprits of some practices that cause energy wastage in the lecture halls 


\section{Leave appliances plugged in when not in use}

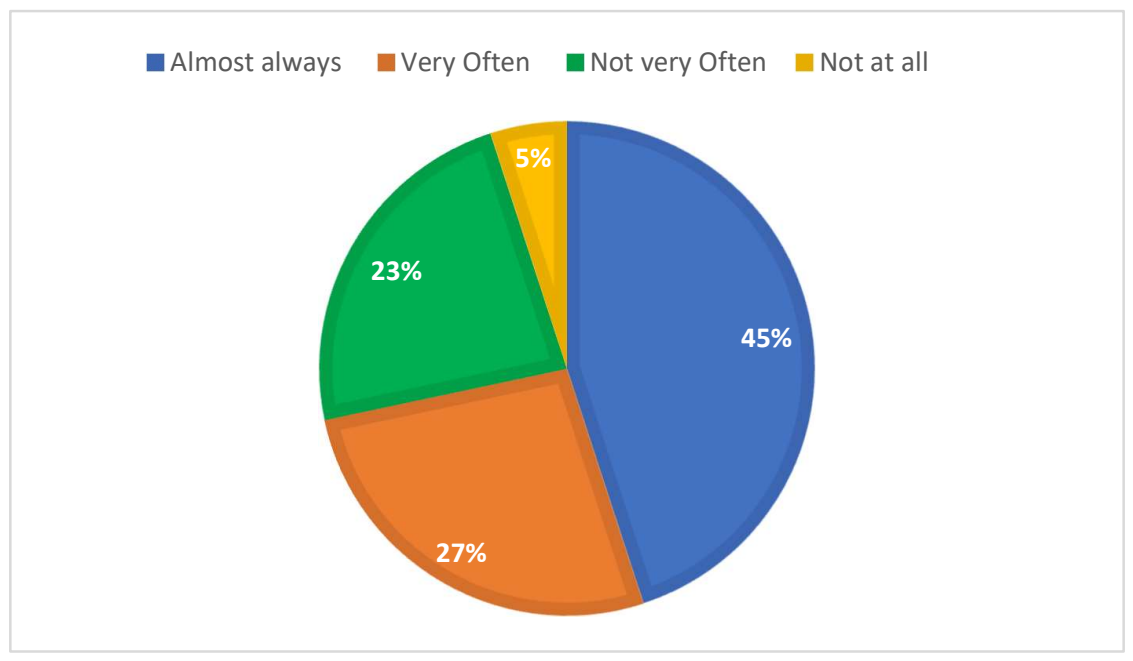

Figure 8. Management responses on the question: Leave appliances plugged in when not in use

Figure 8 above also shows that $45 \%$ (majority) of the respondents admitted to leave appliance plugged in when not in use either Almost always or very often. Both Figure 7 and Figure 8 as a result show consistent results that managements' practices lead to energy wastage in the lecture halls.

However, most management respondents asserted in the study that they do report electrical faults to school electricians. Figure 9 below shows the levels of agreement of the management respondents in the category of reporting electrical faults to school electricians.

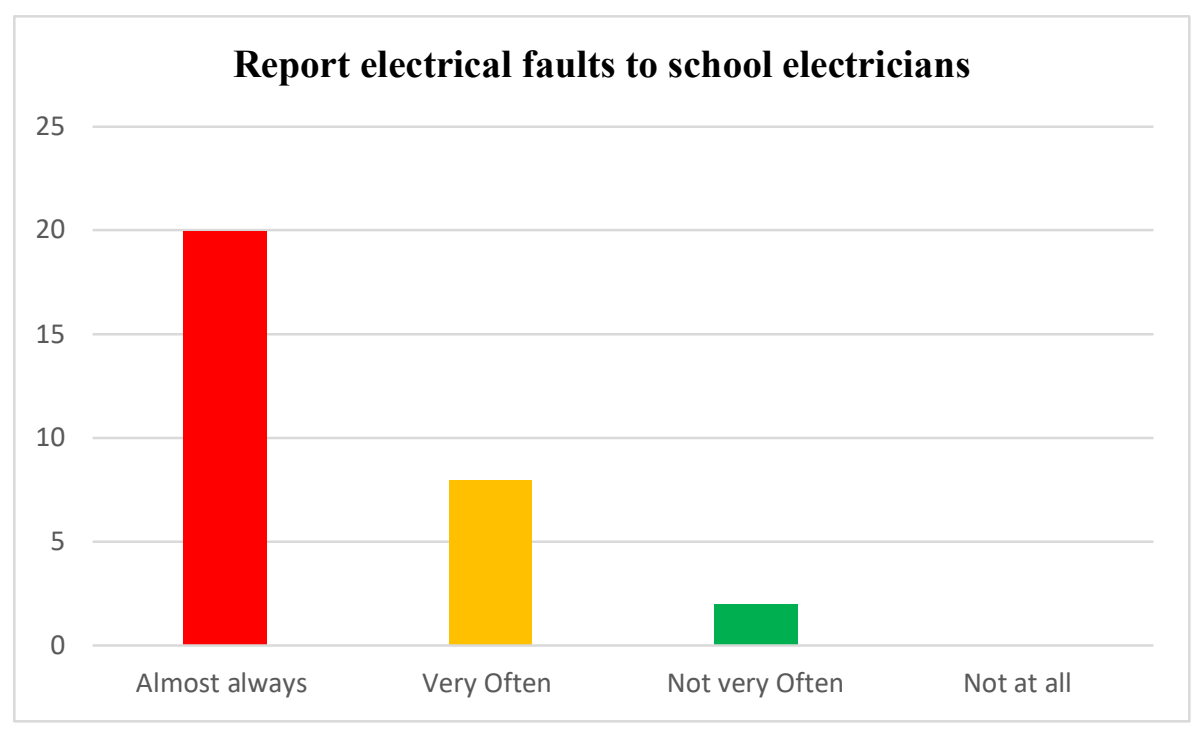

Figure 9. Management responses on the question: reporting electrical faults to school electricians. 


\section{Discussion}

5.1. Summary of findings

This chapter of the research presented the results obtained from the field study and went on further to discuss what they possibly implied. Prime among these findings were the fact that quite contrary to what run across in some previous research reviewed in literature, users of lecture halls (students) engage in inefficient resource use practices and therefore excessive consumption. The findings also revealed that management (comprising lecturers and head of departments) engage in some energy wastage practices that could contribute to the overall energy wastage in the lecture halls. There may certainly be other factors that could cause energy wastage in the lecture halls but were not the focus of this study. The next and final chapter of the research will document a summary of the findings; relating them to how they have met the research objectives and suggest recommendations in response to curbing energy in the KNUST lecture halls.

\subsection{Lecture Hall Users and Electric Energy Consumption}

From the literature survey, it was identified that electric energy consumption by lecture hall users (students) were their use of electrical gadgets and appliances. Prime among the electric consumption were:

Leaving cables plugged in after using sockets (which drains energy by the phenomenon called phantom power).

Leaving appliances on when they were not really in use or not needed

Literature also identified wastage caused by management. Electric energy losses were primarily due to:

Failure to provide efficient appliances in lecture halls

5.3. Identify contemporary theories for reducing electric energy wastage in lecture halls

Based on the responses acquired from investigations made during the field survey, it can be realized that occupants on one hand already engage in energy efficient behavior. From the responses, a majority of the occupants claimed to comply to best practices of energy use in their daily activities. However, it was realized that management on the other hand had some retrofitting to do in terms of the provision of efficient appliances. Management was also found lacking in the area of sensitizing the occupants on electric energy. Regular maintenance of the electrical systems of the lecture hall must also be prioritized by the management.

\section{Discussion}

Based on the findings of the study, the following are the recommendations made in response to curbing the state of energy wastage in the lecture hall.

\subsection{Energy Conservation Measures to be Employed by Management}

The study revealed that lecturers mostly engage in energy wastage practices, maybe due to busyness in the lecture hall when they are lecturing. As result of this, the researcher 
recommends that lecturers assign their teaching assistants or class representatives to take care of their electronic gadgets and therefore keep in track of their energy usage so that they may turn off or unplug appliances when they are not being used in the time of lecture by the lecturer. Nevertheless, it is also recommended that lecturers be mindful of their practices as they cost the university in terms of bills and therefore should try their best to monitor their energy usage and hence conserve energy.

6.2. Policy Interventions to be Introduced by University Management to Curb Electric Energy Wastage.

The researcher recommends that the management of the university introduce policies that would allow for regular large-scale maintenance of electric gadgets and appliances used by lecturers in order rectify faults that can result in supply losses. It is also recommended that sockets have some devices that could check faulty appliances when they are plugged in. Again, management of the university may also strengthen the prompt repairs of electrical faults when they are reported as the study shows that both students and lecturers almost always report electrical faults.

Author Contributions: Conceptualization, D.D. and A.M.; methodology, P.N.; software, P.N.; validation, D.D., and A.M.; formal analysis, P.N.; investigation, P.N.; resources, P.N.; data curation, P.N.; writing-original draft preparation, P.N.; writing-review and editing, P.N.; visualization, P.N.; supervision, D.D.; project administration, D.D.; funding acquisition, P.N. All authors have read and agreed to the published version of the manuscript.

Funding: This research received no external funding

Data Availability Statement: Not applicable

Acknowledgments: The authors would like to thank the Department of Architecture, they aided in acquiring professional knowledge.

Conflicts of Interest: The authors declare no conflict of interest.

\section{References}

1. Seger, B., Global Energy Consumption: The Numbers for Now and in the Future.: Technical University of Denmark. ,2016.

2. International Energy Agency (IEA), 2009. Key world energy statistics. Available online http://www.iea.org/textbase/nppdf/free/2009/key_stats_2009.pdf. Accessed: 23 May 2020

3. Ministry of Energy. Towards efficient lighting and appliance market in Ghana, Accra: Ministry of Energy, 2011.

4. Energy Commission. Energy Efficiency Standards and Appliance Labelling Regulation, Accra: Energy , 2005.

5. Energy Commission. Energy efficiency drive-the story of Ghana, Accra: Energy Commission, 2013.

6. Eurostat. Manual for Statistics on Energy Consumption in Households. Luxembourg: European Commission, 2013.

7. C. Beggs, Energy Management Supply and Conservation, 2nd Edition ed., London: Routledge, 2009.

8. Poznaka, L., Laicane, I., Blumberga, A. \& Rosa, M. Analysis of electricity user behaviour: case study base on results from an extended household survey. Energy Procedia, 2015, 72, pp. 79-78.

9. United States Environmental Protection Agency. A Framework for Sustainability Indicators, s.l.: United States Environmental Protection Agency, 2014.

10. United Nations Foundation. Realizing the potential of Energy Efficiency- Targets, Policies and Measures for G8 countries. Washington, D. C.: United Nations Foundation, 2007.

11. Wolde-Rufael, Y.: Electricity consumption and economic growth: a time series experience for 17 African countries. Energy Policy,2006, 34(10), 1106-1114.

12. Handbook of Energy Use and Conservation, Massachusetts: WaterPlow Press. Wagner, S. M. \& Mellblom, P. C. N., 2008.

13. Akpan, U.F., Akpan, G.E.: The contribution of energy consumption to climate change: a feasible policy direction. J. Energy Econ. Policy, 2012, 2(1), 21-33.

14. Lopez, J. Energy Use Behaviour Change:, Orange: Chapman University Press, 2012.

15. United States Energy Information Administration. International Energy Outlook, Washington, D.C.: s.n., 2017.

16. Seger, B., 2016. Global E 
17. Kwame Nkrumah University of Science and Technology. Lecture halls. [Online] Available at: knust.edu.gh [Accessed 1 February 2020]

18. De Vaus, D. A. Research Design in Social Research. London: SAGE Publications Inc..69 Emeakaroha, A., Ang, C. S. \& Yan, Y., 2012. Challenges in Improving Energy Efficiency in a University Campus Through the Application of Persuasive Technology and Smart Sensors. Challenges, 2001 pp. 290-318.

19. Wagner, S. M. \& Mellblom, P. C. N. The Next Generation of energy Efficient Building Design: where are we and where should we be going?, Minneapolis: Meyer, Scherer \& Rockcastle Ltd. , 2008.

20. K. Frank and G. D.Yogi, Hand Book of Energy Efficiency and Renewable Energy, F. Kreith and D. Y. Goswami, Eds., New York, CRC Press, pp. 22.1-22.30, 2007.

21. Climate Change: Synthesis Report, Geneva, Switzerland: Intergovernmental panel on Climate Change. Paine, E. D., 2007.

22. Gielen, D.; Boshell, F.; Saygin, D.; Bazilian, M.D.; Wagner, N.; Gorini, R. The role of renewable energy in the global energy transformation. Energy Strategy Rev. 2019, 24, 38-50.

23. Lopez, J. Energy Use Behaviour Change:, Orange: Chapman University Press, 2012.

24. Mel George, Energy Audit of IIT Bambay campus - A case of Indian Institute of Technology, Bombay

25. Kotler and Roland, Strategic Frames of Reference: The Key Tools of Strategy Determination, their Principles, and How they Interact, 2010.

26. X Han, F Williamson, GA Bhaduri, A Harvey, L Šiller. The Journal of Supercritical Fluids 106, 140-144, $14,2015$.

27. Patrick Beirnacki, Snowball Sampling: Problems and Techniques of Chain Referral Sampling, 2018. 